\title{
Geographical Epidemiology of Cardiovascular Diseases in Zanjan Province: Analysis of Groups from the International Classification of Diseases, $10^{\text {th }}$ Revision
}

\author{
Ahmad Jalilvand $^{1}(\mathbb{D})$, Roghayeh Soleimani ${ }^{2}(\mathbb{D})$, Mohsen Soleimani ${ }^{3 *(D)}$
}

1. Dept. of Pathology, School of Medicine, Zanjan University of Medical Sciences, Zanjan, Iran

2. Dept. of Education and Psychology, Islamic Azad University of Zanjan, Zanjan, Iran

3. Dept. of Medical Informatics, Ayatollah Mousavi Hospital, Zanjan University of Medical Sciences, Zanjan, Iran

\begin{tabular}{|c|c|}
\hline Article Info & ABSTRACT \\
\hline doi $10.30699 / j a m b s .28 .127 .90$ & \multirow{2}{*}{$\begin{array}{l}\text { Background \& Objective: Cardiovascular diseases (CVDs) are the most common } \\
\text { chronic diseases and the leading cause of death in the world and in Iran. The aim of } \\
\text { this study was to explore the geographical epidemiology of CVDs in the province } \\
\text { of Zanjan, Iran. }\end{array}$} \\
\hline $\begin{array}{l}\text { Received: 2019/11/14; } \\
\text { Accepted: 2020/01/16; }\end{array}$ & \\
\hline Published Online: 01 Mar 2020; & \multirow{2}{*}{$\begin{array}{l}\text { Materials \& Methods: This cross-sectional study was carried out at Zanjan } \\
\text { University of Medical Sciences. Patients with a discharge diagnosis of CVDs (I00-I99 } \\
\text { group of ICD-10 codes) who were hospitalized from 2012-2019 were selected as a } \\
\text { study sample. All spatial analyses were performed in ArcGIS 10.7, and descriptive } \\
\text { analysis was conducted by R (v3.6.0) and RStudio (v1.2.1335) software. }\end{array}$} \\
\hline $\begin{array}{l}\text { Use your device to scan and read the } \\
\text { article online }\end{array}$ & \\
\hline 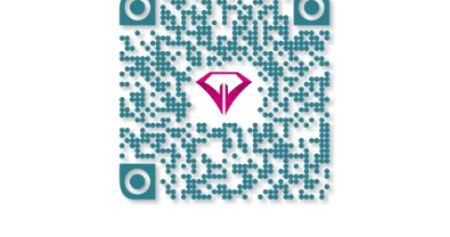 & $\begin{array}{l}\text { Results: The ischemic heart disease subgroup accounted for the majority of CVD } \\
\text { cases ( } 43.8 \%) \text {, while acute rheumatic fever }(0.03 \%) \text { was the least common contributor } \\
\text { to CVD. Men had a higher rate of CVD }(53.1 \%) \text { than women }(46.9 \%) \text {. The mean age } \\
\text { of all CVD subgroups was } 56.88 \text { years, and the mean length of stay of all CVD } \\
\text { subgroups was } 114.2 \text { hours. Zanjan city }(57.4 \%) \text { had the greatest incidence rate of } \\
\text { CVDs in Zanjan province, Iran. }\end{array}$ \\
\hline \multirow{3}{*}{$\begin{array}{l}\text { Corresponding Information: } \\
\text { Mohsen Soleimani, } \\
\text { Dept. of Medical Informatics, } \\
\text { Ayatollah Mousavi Hospital, Zanjan } \\
\text { University of Medical Sciences, } \\
\text { Zanjan, Iran } \\
\text { E-Mail: } \\
\text { Mohsensoleymani66@gmail.com }\end{array}$} & Conclusion: Geographical epidemiology studies can identify the pattern of CVD \\
\hline & $\begin{array}{l}\text { distribution in different areas and can be helpful in preventing CVDs. A spatial- } \\
\text { temporal pattern of CVD distribution provides crucial information for health } \\
\text { development planning in Iran. The findings of this study provide useful information } \\
\text { for health authorities in Ayatollah Mousavi Zanjan, Iran, to plan CVD prevention } \\
\text { programs. }\end{array}$ \\
\hline & $\begin{array}{l}\text { Keywords: Cardiovascular Diseases, Epidemiology,Geographic information } \\
\text { systems, International classification of diseases }\end{array}$ \\
\hline (c) (1) (9) & $\begin{array}{l}\text { iss article distributed under the terms of the Creative Commons Attribution-noncommercia } \\
\text { oncommercial usages with proper citation. }\end{array}$ \\
\hline
\end{tabular}

\section{Introduction}

Chronic diseases are the main cause of mortality and morbidity in the world. In most developed countries, increasing chronic disease prevalence rates, escalating costs, and the growing elderly population have led healthcare authorities to consider innovative approaches to manage patients and improve the quality of care (1). The World Health Organization (WHO) defines a chronic disease as "a long-term disease that progresses slowly" (2). According to WHO reports, the main cause of mortality and disability in 2020 will be chronic diseases, which, if not managed successfully, will become a serious and costly problem in health care systems. Cardiovascular diseases (CVDs) are the most common non-communicable chronic diseases in the world. According to the WHO, CVDs were the main cause of 17.5 million deaths $(31 \%)$ in 2014. They forecast that this number will reach $35-65 \%$ by 2025
(3). CVDs are the main cause of mortality in Iran (46.04\%), including in the province of Zanjan (42\%) (4).

Previous studies showed that the incidence of CVDs can vary in different geographic areas according to risk factors, age, sex, and ethnicity (5). For example, the prevalence of CVDs has been found to be significantly higher in the northern part of Kerman province of Iran in comparison to the southern part (6). Most incidences of CVDs in Jahrom, Fars, Iran, were found in men $(53 \%)$ and most cases occurred in the age group of 42 83 years (7). Geographical epidemiology studies have been conducted to find the causes and distribution patterns of diseases, injuries, and deaths in different areas. The results of geographical epidemiology studies have a major role in increasing people's life expectancy and improving healthcare quality. The 
spatial aspects of CVDs can notify the targeting of healthcare interventions, especially in areas with high CVD prevalence (8).

The aim of this study was to explore the geographical epidemiology of the incidences of different CVD subgroups in the province of Zanjan, Iran, from 20122019. The results of this study can help practitioners to evaluate the population health state and encourage further studies to identify the risk factors associated with CVDs and provide health and social care interventions, particularly in areas with high incidences of CVDs.

\section{Materials and Methods}

\section{Study Area}

Zanjan is one of the 31 provinces of Iran located in northwest. It has eight cities and its center is Zanjan city. The province of Zanjan covers an area of 291.27 $\mathrm{km}^{2}$, and its population is about $1,057,461$ people (9).

\section{Data Gathering}

CVDs incidence data were obtained from the databases of ten Hospital Information Systems (HIS) at Zanjan University of Medical Sciences (ZUMS). We collected patients' addresses, gender, age, length of stay, ICD-10 discharge diagnosis code and admission date from the HIS database. CVDs were classified into ten subgroups based on the International Classification of Diseases $10^{\text {th }}$ revision (ICD-10) (Table 1). The ICD10 codes between I00 and I99 were selected as cardiovascular diseases. There were 86204 CVD cases in the study area during 2012-2019, but 6540 cases were excluded because of incomplete patients' residential address information, patients with other cities' residential addresses, or re-admission with the same diseases during one year. This study was approved by the Ethics Committee of ZUMS (Code IR.ZUMS.REC.1398.056).

\section{Data Analysis}

This was a cross-sectional study conducted at Zanjan University of Medical Sciences. Data analysis was performed using ArcGIS 10.7, R (v3.6.0) and Rstudio (v1.2.1335) software. The Chi-Square statistic was used for examining the relationships between categorical variables.

\section{Results}

A total of 86,204 CVDs were registered in Zanjan province hospitals from 2012-2019. The ICD-10 codes of 79,664 cases were between I00 and I99, with an incidence of 7530 CVDs per 100,000 people. The mean age of CVD patients was $61.88 \pm 17.10$ years, and the mean length of stay (LOS) was 107.23 \pm 219.62 hours. Men had a higher rate of CVDs $(53 \%)$ than women $(47 \%)$.

The ischemic heart disease (IHD) subgroup had the greatest incidence rate of CVDs (43.8\%), and the prevalence rate of the ARF subgroup was the lowest $(0.03 \%)$. The highest mean age was in the CD subgroup $(67.5 \pm 15.9$ years), and the lowest mean age was in the ARF subgroup (24.6 \pm 23.9 years). The discrepancy between the highest and the lowest mean age was 42.9 years. The mean LOS of CVDs was the highest in the PHDDPC subgroup (198 \pm 258.2 hours) and the lowest in the HD subgroup (71.4 \pm 174.7 hours). The discrepancy between the highest and the lowest mean LOS of CVD subgroups was 126.6 hours (Table 1$)$.

Table 1. CVD subgroups' incidence rates by sex in Zanjan province, Iran, from 2012-2019

\begin{tabular}{|c|c|c|c|c|c|c|}
\hline $\begin{array}{l}\text { ICD-10 } \\
\text { codes }\end{array}$ & $\begin{array}{c}\text { CVD } \\
\text { Subgroups }\end{array}$ & $\mathbf{N}(\%)$ & Women (\%) & $\begin{array}{l}\text { Men } \\
(\%)\end{array}$ & $\begin{array}{c}\text { AGE (Year) } \\
\overline{\overline{\mathbf{X}}} \pm \text { SD }\end{array}$ & $\begin{array}{c}\text { LOS (Hour) } \\
\overline{\overline{\mathbf{X}} \pm \text { SD }}\end{array}$ \\
\hline $\mathrm{I} 00-\mathrm{I} 02$ & Acute rheumatic fever (ARF) & $26(0.03)$ & $12(46.2)$ & $14(53.8)$ & $24.6 \pm 23.9$ & $121.1 \pm 88.6$ \\
\hline I05-I09 & Chronic rheumatic heart diseases (CRHD) & $1003(1.3)$ & $616(61.4)$ & 387 (38.6) & $60.7 \pm 17.2$ & $146.1 \pm 207.3$ \\
\hline I10-I15 & Hypertensive diseases (HD) & $7327(9.2)$ & $4891(66.8)$ & $2436(33.2)$ & $65.1 \pm 14.3$ & $71.4 \pm 174.7$ \\
\hline $\mathrm{I} 20-\mathrm{I} 25$ & Ischemic heart diseases (IHD) & $34891(43.8)$ & $15309(43.9)$ & $19582(56.1)$ & $62 \pm 13.4$ & $89.5 \pm 183.8$ \\
\hline I26-I28 & $\begin{array}{l}\text { Pulmonary heart disease and diseases of } \\
\text { pulmonary circulation (PHDDPC) }\end{array}$ & $2216(2.8)$ & $1104(49.8)$ & $1112(50.2)$ & $59.9 \pm 23.8$ & $198 \pm 258.2$ \\
\hline I30-I52 & Other forms of heart disease (OFHD) & $13104(16.4)$ & $6381(48.7)$ & $6723(51.3)$ & $65.7 \pm 18.1$ & $118.7 \pm 200.3$ \\
\hline I60-I69 & Cerebrovascular diseases (CD) & $11478(14.4)$ & $5438(47.4)$ & $6040(52.6)$ & $67.5 \pm 15.9$ & $162.1 \pm 347.6$ \\
\hline I70-I79 & $\begin{array}{l}\text { Diseases of arteries, arterioles and capillaries } \\
\text { (DAAC) }\end{array}$ & $1261(1.6)$ & $479(38)$ & $782(62)$ & $60.4 \pm 19.2$ & $133.3 \pm 266.3$ \\
\hline I80-I89 & $\begin{array}{l}\text { Diseases of veins, lymphatic vessels and lymph } \\
\text { nodes, not elsewhere classified (DVLL) }\end{array}$ & $7902(9.9)$ & $2918(36.9)$ & $4984(63.1)$ & $44.9 \pm 19.9$ & $84.3 \pm 134.2$ \\
\hline \multirow[t]{2}{*}{ I95-I99 } & $\begin{array}{l}\text { Other and unspecified disorders of the } \\
\text { circulatory system (OUDCS) }\end{array}$ & $456(0.6)$ & $224(49.1)$ & $232(50.9)$ & $61.5 \pm 21.9$ & $131 \pm 227.7$ \\
\hline & Total & $79664(100)$ & 37372 (47) & $42292(53)$ & $61.88 \pm 17.10$ & $107.23 \pm 219.62$ \\
\hline
\end{tabular}


Figure 1 demonstrates that the incidence rate of most CVD subgroups was the highest in 2019. The IHD subgroup contained the majority of CVD incidences from 2012-2019. The analysis of CVD prevalence rates from 2012-2019 shows that the rate has increased from 7222 cases in 2012 to more than 14,115 cases in 2019 .

Zanjan city had the most CVD incidences in Zanjan province $(57.4 \%)$. The prevalence rate of CVDs in Soltanieh city was the lowest $(2.5 \%)$. The mean age of CVD patients increased from $56.85 \pm 15.39$ years in 2012 to $59.24 \pm 18.93$ years in 2019 . The lowest mean age of CVD patients was found in Khodabandeh city (52.58 \pm 20.13 years), and the highest mean age of CVD patients was found in Tarom city (59.41 \pm 15.64 years).

The mean LOS of CVD patients decreased from $133.2 \pm 293.2$ hours in 2012 to $105.8 \pm 145.7$ hours in 2019. The lowest mean LOS was reported in the HD subgroup (76.9 \pm 165.3 hours). Meanwhile, the mean
LOS of the PHDDPC subgroup was the highest (197.4 \pm 244.4 hours) (Table 1). The shortest mean LOS of CVDs by city was that of Abhar city (103.2 \pm 144.7 hours); the mean LOS of CVDs in Mahneshan city was the longest (137.5 \pm 183.1 hours).

The results of this study showed a significant relationship between the incidence of CVDs and age $(P<0.0001)$. The IHD subgroup incidence rate was highest for the age group of 50-70 years. Meanwhile, in the DVLVLN subgroup, CVDs were more common in the age group of 30-40 years (Figure 2).

Figure 3 demonstrates the geographical distribution of the CVD subgroups in Zanjan province, Iran. It shows that the northern (Zanjan city) and southern regions (Khodabandeh and Abhar cities) of the study area had the highest incidence rates of CVD subgroups.
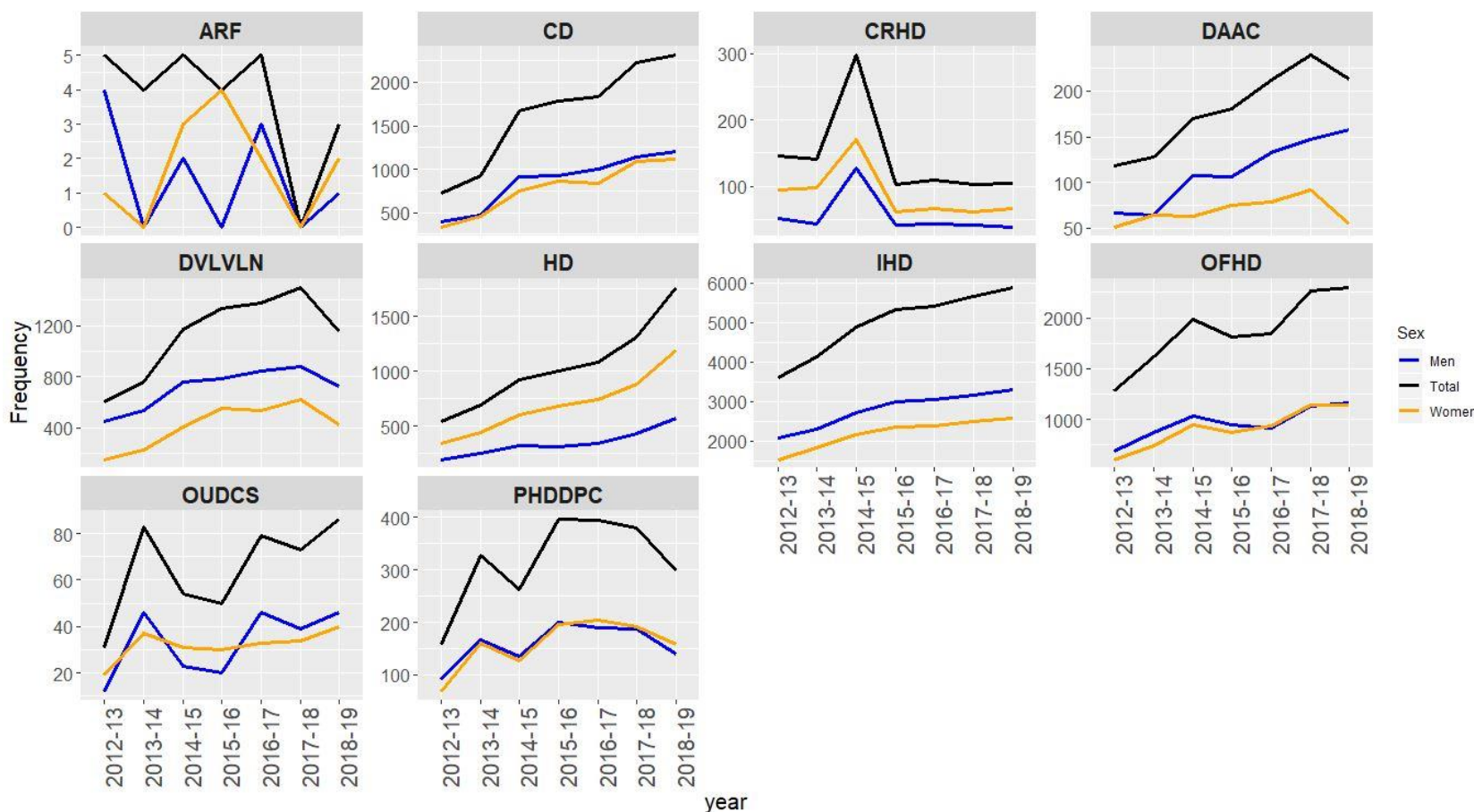

Figure 1. CVD subgroups' incidence rates by year in Zanjan province, Iran.from2012-2019 


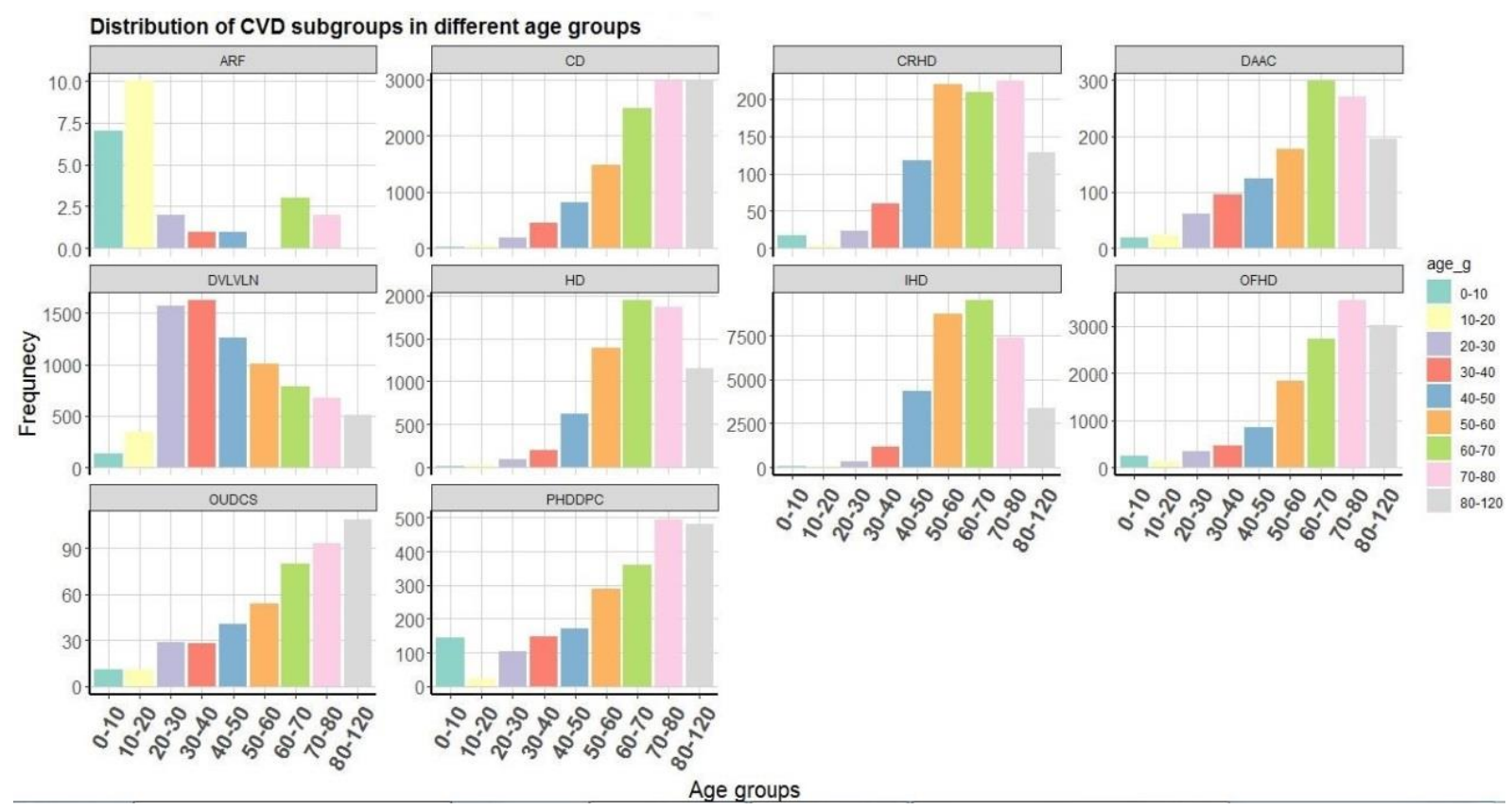

Figure 2. Age distribution of CVDs in Zanjan province, Iran, from 2012-2019

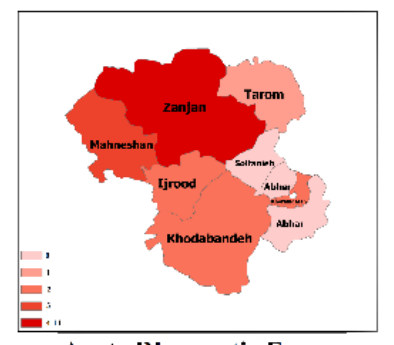

Acute Rheumatic Fever

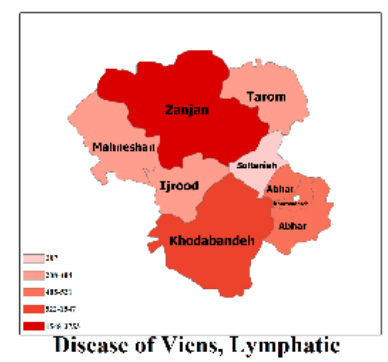

Vessles and Iymph Nodes, No elsewhere Classified

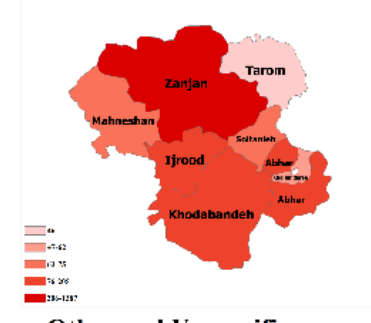

Other and Unspecifies

Disorders of the Circulatory System

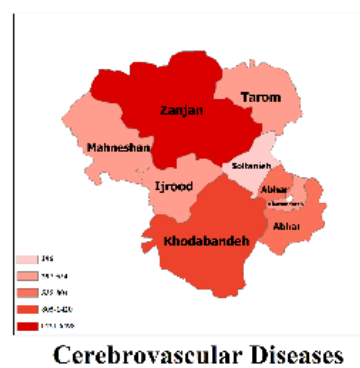

Cerebrovascular Diseases

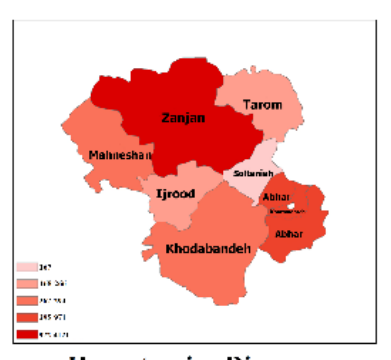

Hypertensive Diseases

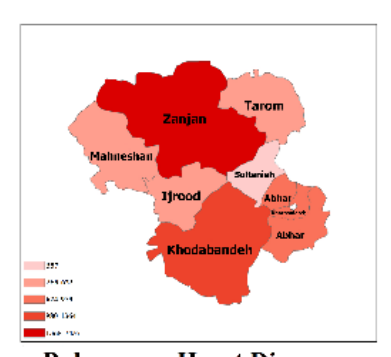

Pulmonary Heart Disease

and Disease of Pulmonary Circulation

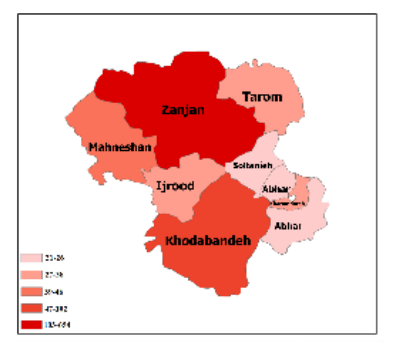

Chronic Rheumatic Heart

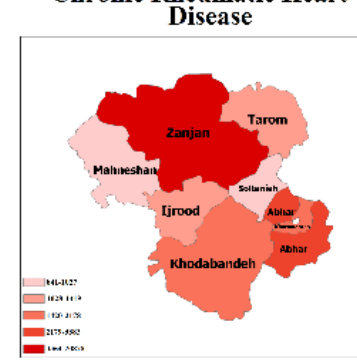

Ischemic Heart Diseases
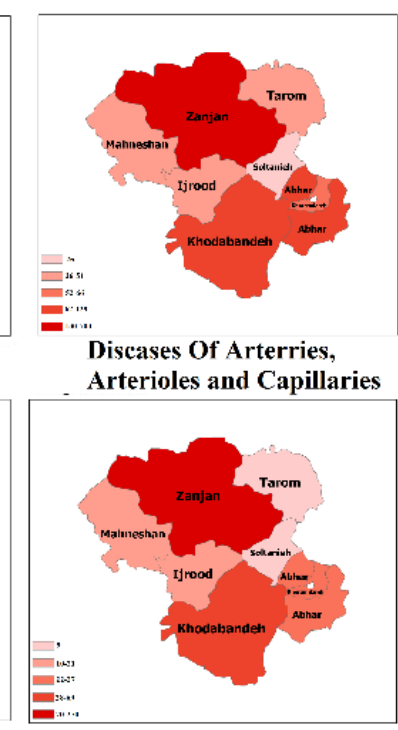

Other Form of Heart Diseases

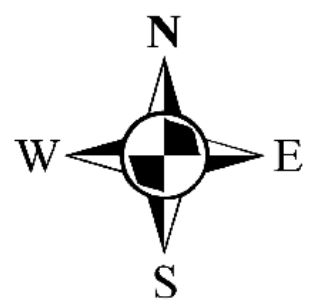

Figure 3. Geographical distribution of CVDs subgroups at the county level in Zanjan Province, Iran 


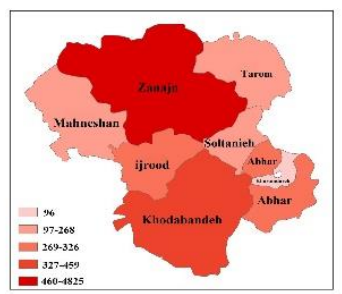

2012-2013

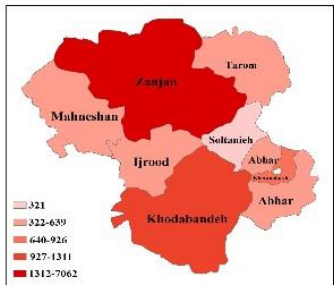

2016-2017

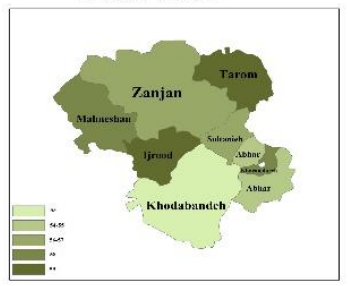

Mean age of CVD

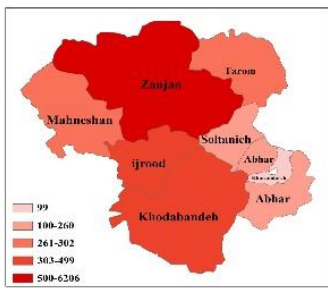

2013-2014

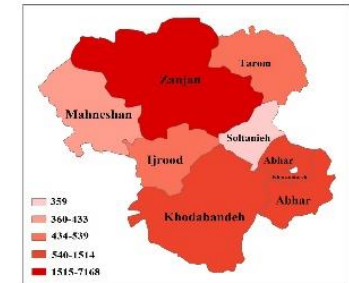

2017-2018

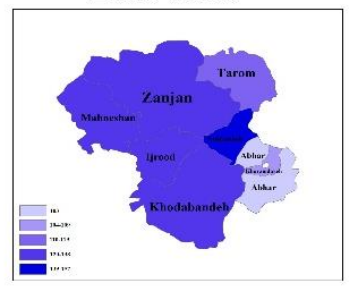

Mean LOS of CVD

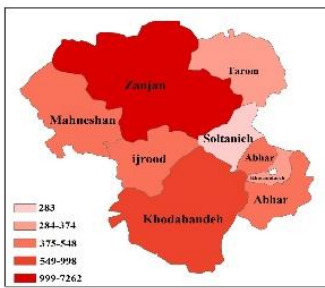

2014-2015

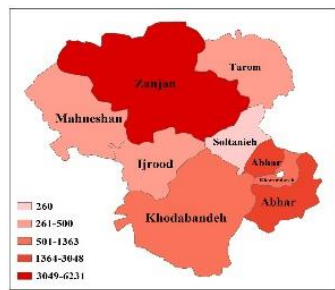

2018-2019

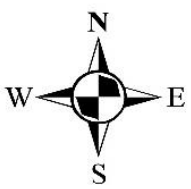

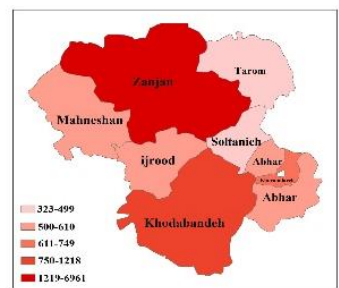

2015-2016

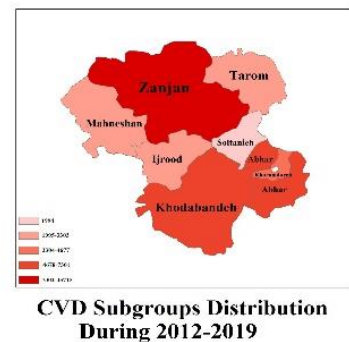

During 2012-2019

Figure 4. Geographical distribution of CVDs subgroups by year in Zanjan Province, Iran during 2012-2019

The results of this study showed that the prevalence rate of $\mathrm{CD}$ and $\mathrm{HD}$ subgroups were increased more than other CVD subgroups in Zanjan province during 2012-2019, while the prevalence rate of IHD subgroup was decreased. The incidence rate of CVD subgroups in Zanjan city during 2012-2019 was as follows: ARF subgroup from $(0.083 \%)$ to $(0.016 \%)$, CD subgroup from $(8.65 \%)$ to $(18.96 \%)$, CRHD subgroup from $(2.064 \%)$ to $(0.789 \%)$, DAAC subgroup from $(1.693 \%)$ to $(1.417 \%)$, DVLVLN subgroup from $(8.505 \%)$ to $(7.889 \%)$, HD subgroup from $(8.505 \%)$ to (10.85\%), IHD subgroup from $(48.26 \%)$ to $(42.02 \%)$, OFHD subgroup from $(18.74 \%)$ to $(15.23 \%)$, OUDCS subgroup from $(0.495 \%)$ to $(0.451 \%)$ and PHDDPC subgroup from $(2.002 \%)$ to $(2.64 \%)$.

The incidence rate of CVD subgroups in other cities of Zanjan province during 2012-2019 was as follows: HD (from $3.66 \%$ to $19.42 \%$ ) and OFHD (from $11 \%$ to $16.22 \%$ ) subgroups' occurrence rate was increased in Abhar city, while the incidence rate of IHD subgroup (from $64.83 \%$ to $43.96 \%$ ) was decreased. The most increasing occurrence rate of CVD subgroups in Khoramdareh city was at HD (from $3.13 \%$ to $18.5 \%$ ) and OFHD subgroups (from $5.21 \%$ to $18.6 \%$ ), but IHD subgroup's incidence rate was decreased (from $65.6 \%$ to $39.6 \%$ ). The occurrence rate of DVLVLN subgroup was increased (from $7.3 \%$ to $13.02 \%$ ), but IHD subgroup's incidence rate was decreased (from 36.44\% to $40.02 \%$ ) in Khodabandeh city. HD subgroup's incidence rate was increased (from $6.91 \%$ to $11.19 \%$ ), while CD subgroup's occurrence rate was decreased (from $12.9 \%$ to $16.21 \%$ ) in Soltanieh city. CD (from
$8.55 \%$ to $16.88 \%$ ) and HD (from $7.43 \%$ to $13.46 \%$ ) subgroups' incidence rate was increased more than others in Tarom city, while OFHD (from $21.18 \%$ to $18.16 \%$ ) and IHD (from $49.44 \%$ to $39.31 \%$ ) subgroups' incidence rate wasdecreased. CD (from $10.61 \%$ to 18.94 ) and HD (from $7.87 \%$ to $10.24 \%$ ) subgroups' occurrence rate was increased in Ijrood city, while IHD (from $44.17 \%$ to $40.16 \%$ ) and DVLVLN (from $13.69 \%$ to $7.42 \%$ ) subgroups' incidence rate was decreased. The incidence rate of CD subgroup was increased (from $11.96 \%$ to $18.49 \%$ ) and IHD subgroup's occurrence rate decreased (from $45.94 \%$ to $37.80 \%$ ) in Mahneshan city.

\section{Discussion}

This was the first study conducted in Zanjan province, Iran, to identify the spatial-temporal patterns of CVDs incidences. Geographical epidemiology analysis plays an important role in classifying geographic diversity patterns. CVDs are the leading cause of morbidity, mortality, disability, and rising medical costs in the world (10). The results of this study showed that the prevalence of CVDs has increased from 2012-2019 in Zanjan province, Iran. The prevalence patterns of CVDs in different regions differed, and the incidence rates of CVDs varied in different areas. The IHD subgroup had the greatest prevalence of CVDs in Zanjan province, Iran (43.8\%).

IHD is the most common cause of death and disability in developed countries and is associated with greater financial burdens than other diseases. Annually, one million patients with acute IHD are registered in 
hospitals in the United States (11). The results of a study on 262 patients showed that $52.1 \%$ had some form of atherosclerosis and that $85.2 \%$ of patients over 50 years old and $17.3 \%$ of adolescent patients had atherosclerosis. A study conducted in Ardabil province, Iran, showed that IHD is more prevalent in men than in women and that the most prevalent risk factors were smoking and hypertension (10). The results of a similar study on 1,000 hospitalized patients at Gilan University of Medical Sciences showed that the prevalence of IHD was greater in men, which is consistent with the results of the current study (11).

A total of 2392 patients with CVDs were registered in hospitals in Jahrom city in Fars, Iran. Of these patients, $53.2 \%$ were women and $46.8 \%$ were men, which conflicts with the results of the current study. The mean age of patients was $60 \pm 12.5$ years, and the majority of patients were in the age group of $42-83$ years, which is consistent with the results of this study (7). In another study, the prevalence of CVDs was $19.4 \%$ among the patients within the age group of 30 79 years in Isfahan province, Iran. CVDs were more prevalent among women than men, which conflicted with the results of this study (12).

Most CVDs were observed in men between 69-60 years of age in Zanjan city. The results of recent studies in Iran and other countries showed that the morbidity and mortality rates are greater in men and for people in the age group of 69-60 years, which is consistent with the result of this study $(6,13)$. The number of CVD patients has increased in recent years in Zanjan province, and the quality of medical equipment has been improving. The accurate and timely diagnoses of CVDs have reduced the LOS in hospitals. Further studies are required to determine which risk factors increase the prevalence of CVDs in these areas.

The mean age and mean LOS of CVDs in this study were consistent with the results of other studies. The mean LOS of CVDs in Jahrom, Iran, was 5.3 \pm 1.63 days, and the mean age of patients was $60 \pm 12.5$ years (7). The mean LOS of angina disease patients was $5.5 \pm 3$ days in England, and the mean age was 67 years. Moreover, the mean LOS of angina disease patients was 4.1 days in Australia (14).

Geographical epidemiology has been developed in the public health system and is a powerful tool that supports healthcare situation analysis, decisionmaking, research, and surveillance to improve the prevention and control of health problems (15). During this time of global concern about the rising financial burden of healthcare, the cost-cutting implications of geographic epidemiology in the fight against CVDs are significant. Using detailed and relevant data allows practitioners to apply evidence of what takes to design care and support in neighborhoods where they are most needed, thus mitigating the risk of wasting resources (16).

\section{Conclusion}

Geographical epidemiology studies can identify the pattern of CVD prevalence in different areas and can be helpful in CVD prevention. The aim of CVD prevention is to reduce the incidence rate of CVDs, thereby reducing the mortality and morbidity rates associated with CVDs. In the past, the incidence of CVDs has been successfully reduced in the fields of medicine and healthcare. However, some challenges remain in terms of residual CVDs risk, and these require further research. The results of this study showed that the northern (Zanjan city) and southern regions (Khodabandeh and Abhar cities) of the study area had the greatest CVD incidence rates and that the prevalence of the IHD subgroup was high in Zanjan province, Iran. Knowledge of disease status and the spatial and temporal pattern of its distribution is critical information for health development planning in Iran. Determining the spatial and temporal trends of diseases in high-risk areas can help health care professionals to identify the incidence and prevalence patterns of diseases, thus helping in the development of screening programs and therapeutic interventions. In conclusion, this study provides useful information to planners and health authorities regarding CVD prevention in Zanjan province, Iran.

\section{Limitations}

This study had some limitations. Working with Persian textual data in $\mathrm{R}$ and the RStudio statistical program was complicated. By using multiple packages and programming many codes, this limitation was reduced, but it took a long time to clean and classify the relevant information from big data. Another limitation was related to the presence of incomplete or inaccurate HIS patient records, which had to either be modified or excluded. Double coding in the use of ICD-10 diagnostic codes to distinguish CVDs represented another limitation of this study.

\section{Acknowledgments}

This study is a part of Health Systems Research (HSR) results that was financially supported by Zanjan University of Medical Sciences (ZUMS).

\section{Conflict of Interest}

Authors declared no conflict of interest.

\section{References}

1. Cheah J. Chronic disease management: a Singapore perspective. BMJ. 2001;323(7319):990-3. [DOI:10.1136/bmj.323.7319.990]

2. National Centre for Health Statistics definitions: health condition Atlanta: United States Centres for Disease Control and Prevention; [2008]. Available from: 
http://www.cdc.gov/nchs/datawh/nchsdefs/healthco ndition.html.

3. Global, regional, and national age-sex-specific mortality for 282 causes of death in 195 countries and territories, 1980-2017: a systematic analysis for the Global Burden of Disease Study 2017. Lancet. 2018;392(10159):1736-88. [DOI:10.1016/S01406736(18)32203-7]

4. Sarrafzadegan N, Mohammmadifard N. Cardiovascular disease in Iran in the last 40 years: prevalence, mortality, morbidity, challenges and strategies for cardiovascular prevention. Arch Iran Med. 2019;22(4):204-10.

5. Virtanen M, Heikkila K, Jokela M, et al. Long working hours and coronary heart disease: a systematic review and meta-analysis. Am J Epidemiol. 2012;176(7):586-96 [DOI:10.1093/aje/kws139]

6. Rezaeian M, Dehdarinejad A, EsmailiNadimi A, Tabatabaie S. Geographical epidemiology of deaths due to cardiovascular diseases in counties of Kerman province. Iran J Epidemiol. 2008;4(1):35-41.

7. Shahsavari S, Nazari F, KarimyarJahromi M, Sadeghi M. Epidemiologic study of hospitalized cardiovascular patients in Jahrom hospitals in 20122013. CardiovascNurs J. 2013;2(2):14-21.

8. Rezaeian M, Dunn G, St Leger S, Appleby L. Geographical epidemiology, spatial analysis and geographical information systems: a multidisciplinary glossary. J Epidemiol Community Health. 2007;61(2):98-102. [DOI:10.1136/jech.2005.043117]

9. Iran SCo. IRAN Statistical Year Book 2016-2017. Tehran: Statistical Center of Iran; 2017.
10. Gamissi J, Masoumi MT, Hossinian A. Spatiotemporal distribution of coronary heart disease by geographic information system ARC GIS in Ardabil province. J Ardabil Univ Med Sci. 2017;17(2):17488

11. Barzigar A, Manzar H. Evaluation of risk factors and associated systemic diseases in 1000 Patients of acute myocardial infarction. J ShahidSadoughiUniv Med Sci .1997; 5: 28-35.

12. Blumenthal R. Executive summary: Heart disease and stroke statistics-2012 update: A report from the American Heart Association. Circulation. 2012;125(1):188-97 [DOI:10.1161/CIR.0b013e3182456d46]

13. Lee J, Alnasrallah M, Wong D, Beaird H, Logue E. Impacts of scale on geographic analysis of health data: An example of obesity prevalence. ISPRS Int J Geo-Inf. 2014;3:1198-210. [DOI:10.3390/ijgi3041198]

14. van der Linde D, Konings EE, Slager MA, et al. Birth prevalence of congenital heart disease worldwide: a systematic review and meta-analysis. J Am College Cardiol. [DOI:10.1016/i.jacc.2011.08.025]

15. Fradelos EC, Papathanasiou IV, Mitsi D, Tsaras K, Kleisiaris CF, Kourkouta L. Health based geographic information systems (GIS) and their applications. Acta Inform Med. 2014;22(6):402-5. [DOI:10.5455/aim.2014.22.402-405]

16. Fuster V, Kelly B. Promoting cardiovascular health in the developing world: A critical challenge to achieve global health. Washington (DC): National Academies Press (US); 2010.

\section{How to Cite This Article:}

Soleimani M, Jalilvand A, Soleimani R. Geographical Epidemiology of Cardiovascular Diseases in Zanjan Province: Analysis of Groups from the International Classification of Diseases, 10th Revision. J Adv Med Biomed Res. 2020; 28 (127) :90-96

\section{Download citation:}

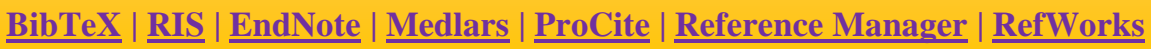

\section{Send citation to:}

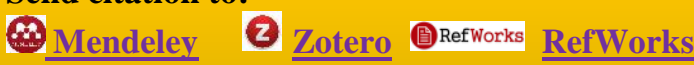

